\title{
Using Simulation to Leverage Digital Transformation of SMEs: A European Perspective
}

\author{
Isabel Ramos \\ University of Minho \\ iramos@dsi.uminho.pt \\ Nekane Aramburu \\ Deusto Business School \\ nekane.aramburu@deusto.es
}

\author{
Klaus North \\ Wiesbaden Business School \\ klaus.north@gmail.com \\ Andreas Hermann \\ University of Münster \\ andreas.hermann@ercis.uni-muenster.de
}

\author{
Stefan Thalmann \\ University of Graz \\ stefan.thalmann@,uni-graz.at \\ Karin Gräslund \\ Wiesbaden Business School \\ Karin.Graeslund@hs-rm.de
}

\author{
Victor Barros \\ University of Minho \\ vfbarros@dsi.uminho.pt
}

\begin{abstract}
Digital transformation is one of the main challenges that SMEs face nowadays. Nevertheless, to a great extent, they lack the necessary capacities and skills to introduce and apply technologies that can support digitalization. As a design science approach, researchers from different European countries have carried out the collaborative research project VOIL to collect and scientifically develop resources and tools to support SMEs in building digital skills. In the context of this project, a tool is developed to assess the digital maturity of SMEs. Moreover, a learning journey based on the use of simulators is proposed together with a minimal viable prototype integrating all developed tools to provide a comprehensive learning environment. Lessons learned from the application of said learning online environment in experimental settings are also shared. The project results contribute to the research that has been carried out within the scope of life long learning, proposing the aggregation of pedagogical strategies that allow self-guided learning in the workplace.
\end{abstract}

\section{Introduction}

Digital technologies are bringing about unprecedented change to business models, products and services, transforming how people work and interact with customers, partners and competitors [1]. The resulting digital transformation (DT) is an ongoing paradigm shift leading to a digital change of society and economy at all levels [2]. Vial [3] describes digital transformation as a process where digital technologies create disruptions. These disruptions trigger strategic responses from organizations that seek to alter their value creation paths while managing the structural changes and organizational barriers that affect digital transformation positive and negative outcomes. This point of view is aligned with conceptual approaches considering that digitalization transcends technology. As pointed out by several authors [4][5], DT implies the embeddedness of IT throughout the organization, organizational processes and functions.

Despite its importance, not all organizations have the knowledge and resources necessary to succeed in digital transformation initiatives. This is particularly true for Small and Medium Enterprises (SMEs), which are important economic actors. According to European Commission [1], SMEs - firms with less than 250 employees and up to a turnover of 50 million Euro account for $99.8 \%$ of non-financial business sector enterprises, two-thirds of total employment $(66.4 \%)$ and slightly less than three-fifths $(56.8 \%)$ of the value generated by the non-financial business sector in the European Union (EU). In the Organisation for Economic Co-operation and Development (OECD) area, SMEs are the predominant form of enterprise, accounting for approximately $99 \%$ of all firms [6]. This economic importance contrasts with a lack of resources and competencies for DT [6][7].

Moreover, these companies may not always be aware of their digital maturity nor define digital growth strategies [8][9]. According to a report by the Digital Innovation Hubs Working Group [10] only $17 \%$ of SMEs have successfully integrated digital technologies into their businesses, compared to $54 \%$ of large companies. While large enterprises understand the opportunities and challenges of the DT, SMEs are still struggling and lack knowledge and resources [11].

However, the COVID-19 pandemic showed the importance of DT, especially for SMEs [12]. Research shows that DT has a positive impact on SMEs' performance and, especially, on their future prospects 
[13]. This is due to the robust innovation potential advantage SMEs can gain from digital technologies [14]. Therefore, SMEs need support in assessing their digital maturity, defining digital growth strategies and developing advanced digital skills to integrate complex technologies in their processes, products and services [15].

This paper proposes an integrated concept aiming at supporting SMEs in assessing their digital transformation maturity, building required digital skills, fostering cross-organizational collaborations, and defining digital transformation strategies. This concept is composed of a collection of integrated resources that together fulfil the aspired SME support. Finally, these resources are made accessible via a prototypical implementation as a web-based platform.

In the following sections, we present an overview of the European perspective of the DT of SMEs (section 2). Section 3 shows the importance of the creation of learning journeys to adopt and align DT of SMEs. The next sections discuss the use of simulation to developing advanced digital capabilities and competencies (section 4) as well as the use of them to experiment with emerging technologies in the SMEs (section 5). Finally, the last section elaborates on lessons learned with this analysis and future steps (section 6).

\section{The digital transformation of SMEs}

SMEs' sustainable competitiveness and growth are increasingly determined by their capability to use digital technologies [16] and tie them into a digital ecosystem [17]. Surveys provide evidence that digitalization has a positive effect on the performance of SMEs [18-20]. This includes dimensions such as growth, market value and profitability as well as social and environmental performance and satisfaction.

Pelletier and Cloutier [21] argue that SMEs have to understand that a successful and consistent digital transformation requires investing not only in IT artifacts and infrastructure (e.g. hardware, software, networks, etc.) but also in the strategic, intellectual, structural, formal and informal, social and cultural dimensions. Yeow, Soh and Hansen [5] found that as an organization shifts towards a digital strategy, misalignments between the emergent strategy and resources give rise to tension and require alignment actions, which iteratively reconfigure organizational resources and refine the strategy to respond to both changes in the environment and internal pressures.

This iterative searching process was also revealed in case studies of 68 German manufacturing SMEs [22]. These studies demonstrate that these firms generally approach Industry 4.0 with caution and are trying to comprehend how to take advantage of business model innovation in value creation, value offer, and value capture. This cautious or reactive view is echoed by a survey of 300 SMEs in the U.K. [23] who still view IT as a necessary cost $(45 \%)$ as opposed to a driver $(20 \%)$ of competitive advantage (see also [24]). The International Data Corporation (IDC) [23] study of 3900 SMEs in 14 countries also states that companies prefer to move forward cautiously, investing in small quick impact projects, setting the stage for more ambitious and demanding projects. Observing other SMEs and learning from them is a widely used approach in this stepwise move towards digitalization [25-26]. Summarizing the above studies, it seems that SMEs adopt quick impact measures, experiment with new solutions, observe their peers and cautiously move forward, mostly following the innovation approach of "Discovery Driven Planning" [27-29], but without a predefined vision regarding a comprehensive digital transformation.

If this vision has to be predefined to guide the transformation success, the challenge is to find appropriate ways and develop capabilities to align technological, organizational and human resources [30] under a consistent strategic perspective.

\section{Developing learning journeys for digital transformation}

SMEs will have to create their individual learning journeys to adopt and align digital technologies. The appropriation of new knowledge demands integrating technology, business and learning strategies in a workplace context [31]. Decision-makers at all levels of the organization must be able to realize the transformative potential of disruptive technologies, understand the needs and opportunities for transforming the business model, design digital transformation initiatives with the support of these technologies, and mobilize the resources necessary for the successful implementation of the initiatives designed [32].

In this transformation and learning journey, individuals and organizations look for orientation and guidance, which can be provided by digital maturity frameworks [33]. In this context, digital maturity means that a company has the necessary organizational capabilities to succeed in digital transformation [34].

For this purpose, we adopted the DIGROW digital maturity framework developed by North, Aramburu and Lorenzo [35], grounded in the micro-foundations of dynamic capabilities [36] and therefore allows to link digitalization to organizational capabilities. Up to now, the framework has been applied by over 500 enterprises, most of which are SMEs. An open dataset for further research is available [9]. Moreover, its simple structure and anchor statements are particularly suited for SMEs 
allowing a practice oriented assessment of current capabilities and digitally enabled business potentials.

The "DIGROW" framework contains four dimensions, which can be seen as challenges (e.g. what are our challenges to sense digitally-enabled growth potentials?) or capabilities (e.g. do we have the capability to sense digitally-enabled growth potentials?). Both views are useful in a self-assessment. Along with dynamic capability theory, the DIGROW framework contains four capacities for each of the four dimensions or capabilities. The assessment is visualized as a "Wheel of digitally enabled growth" (Figure 1).

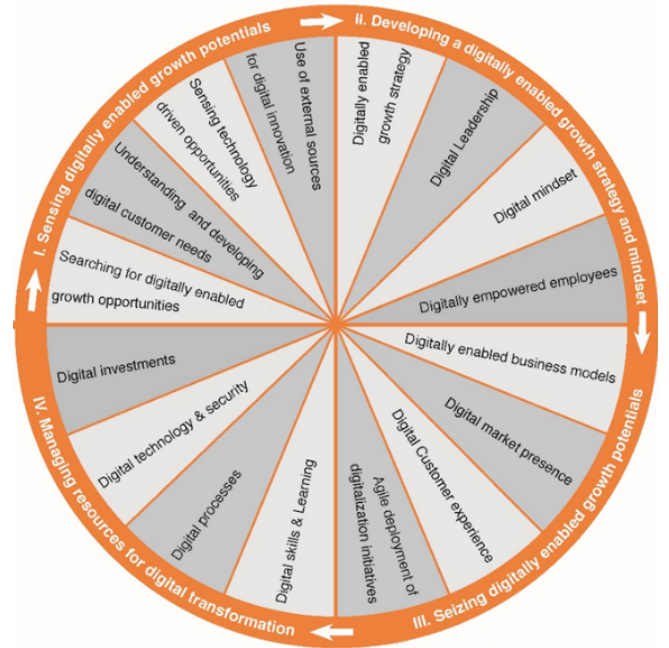

Figure 1. The wheel of digitally enabled growth (Source: [35])

Each of these 16 capacities can be evaluated at five levels described by an anchor statement (i.e. levels 0 \& 1 correspond to a low maturity; levels $2 \& 3$ to a medium maturity level; levels $4 \& 5$ to a high maturity). In a pretest with firms [37], it was found that these five levels would allow a sufficient degree of differentiation. Therefore, the "DIGROW" framework is structured as follows:

1. Sensing digitally-enabled growth potentials: Searching for digitally-enabled growth opportunities, understanding and developing digital customer needs, sensing technologydriven opportunities, use of external sources for digital innovation.

2. Developing a digitally enabled growth strategy and mindset: Digitally enabled growth strategy, digital leadership, digital mindset (attitudes \& behaviors), empowered employees.

3. Seizing digitally-enabled growth potentials: Digitally enabled business models, digital market presence, digital customer experience, agile implementation/deployment of digitalization initiatives.
4. Managing resources for digital transformation: Digital skills \& learning, digital processes, digital technology \& security, digital investments.

The self-assessment of SMEs' owners, managers, and employees can support their learning journey by raising awareness towards required capabilities and creating a shared understanding of what "digitallyenabled growth" means. It also helps develop and communicate a strategy and anchor pilot initiatives in an overall "picture" of digitalization. SMEs are also supported in defining learning objectives (e.g., what do we need to learn to advance from level 2 to level 3?).

The Digital Transformation Competency Model has been developed to assist, in particular educators, in designing and evaluating curricula for the DT of SMEs [35]. There, the capacities making up the dimensions of the DIGROW digital maturity framework have been grouped into different categories (i.e. the four capacities included in each dimension are grouped into two categories). Overall, eight categories have been defined. Moreover, the four dimensions and eight categories have been matched to the 41 e-competencies defined within the European e-Competence Framework (e-CF) version 3.0 [38].

It should be clarified that the capacities of the DIGROW framework refer to the organizational level, that is, they are organizational capacities, while the ecompetencies of the European e-Competence Framework correspond to individual competencies. Therefore, we integrate both organizational and individual levels. Thus, by applying the DIGROW model, we can assess the digital maturity of companies based on the measurement of organizational capacities. Furthermore, the e-competencies linked to the different capacities can also be measured. In this line, we apply the four levels of competence mastery proposed in the European e-competence Framework (i.e., null mastery (0), novice (1), intermediate (2), advance (3)).

In this framework, 'Competence' is defined as a "demonstrated ability to apply knowledge, skills and attitudes for achieving observable results". The structure of the 41 competencies follows a logic of an ICT project with the phases plan - build -run - enable - manage. The framework, therefore, does not fully cover competencies needed for the digital transformation of companies. The result (see table 1) shows that the ecompetencies are not evenly distributed across the DIGROW dimensions. In particular, business and transformation-related competencies are underrepresented in relation to ICT development and deployment. For the sections "Digital mindset" and "digitally empowered employees", there are no corresponding e-competencies. 
Table 1. DIGROW dimensions.

\begin{tabular}{|c|c|c|c|c|}
\hline Areas & $\begin{array}{l}1 \text { Sensing digitally } \\
\text { enabled growth } \\
\text { potentials }\end{array}$ & $\begin{array}{l}2 \text { Developing a } \\
\text { digitally enabled } \\
\text { growth strategy and } \\
\text { mindset }\end{array}$ & $\begin{array}{l}\text { 3 Seizing digitally } \\
\text { enabled growth } \\
\text { potentials \& } \\
\text { transformation }\end{array}$ & $\begin{array}{l}4 \text { Managing resources for } \\
\text { digital transformation }\end{array}$ \\
\hline Categories & $\begin{array}{l}\text { 1.1.Understand and } \\
\text { monitor digital } \\
\text { technologies and their } \\
\text { business potentials. } \\
\text { 1.2.Develop digital } \\
\text { customer needs }\end{array}$ & $\begin{array}{l}\text { 2.1.Review and design } \\
\text { digital business strategy } \\
\text { and business models. } \\
\text { 2.2. Develop a digital } \\
\text { transformation culture. }\end{array}$ & $\begin{array}{l}\text { 3.1.Transform the } \\
\text { organization } \\
\text { 3.2.Design /implement } \\
\text { digital market presence } \\
\text { and customer experience }\end{array}$ & $\begin{array}{l}\text { 4.1.Implement and manage } \\
\text { digital processes } \\
\text { 4.2 Manage digital risks and } \\
\text { cybersecurity }\end{array}$ \\
\hline Competencies & $\begin{array}{l}\text { A.7. Technology } \\
\text { Trend Monitoring } \\
\text { E.1. Forecast } \\
\text { Development } \\
\text { D.11. Needs } \\
\text { Identification } \\
\text { D.5. Sales Proposal } \\
\text { Development }\end{array}$ & $\begin{array}{l}\text { A.1 IS and Business } \\
\text { Strategy Alignment } \\
\text { A.3. Business Plan } \\
\text { Development } \\
\text { A.4. Product / Service } \\
\text { Planning } \\
\text { A.8. Sustainable } \\
\text { Development } \\
\text { E.9. IS Governance } \\
\text { D.9. Personnel } \\
\text { Development } \\
\text { D.3. Education and } \\
\text { Training Provision }\end{array}$ & $\begin{array}{l}\text { E.7. Business Change } \\
\text { Management } \\
\text { E.2. Project and Portfolio } \\
\text { Management } \\
\text { D.10. Information and } \\
\text { Knowledge Management } \\
\text { C.4. Problem } \\
\text { Management } \\
\text { B.4. Solution Deployment } \\
\text { ( see also M7) } \\
\text { E.4. Relationship } \\
\text { Management } \\
\text { D.12. Digital Marketing } \\
\text { D.6. Channel } \\
\text { Management }\end{array}$ & $\begin{array}{l}\text { A.5. Architecture Design } \\
\text { A.6. Application Design } \\
\text { B.1. Application } \\
\text { Development } \\
\text { B.2. Component Integration } \\
\text { B.3. Testing } \\
\text { B.4. Solution Deployment } \\
\text { B.5. Documentation } \\
\text { Production } \\
\text { B.6. Systems Engineering } \\
\text { D.1. Information Security } \\
\text { Strategy Development } \\
\text { D.2. ICT Quality Strategy } \\
\text { Development } \\
\text { E.6. ICT Quality } \\
\text { Management } \\
\text { E.8. Information Security } \\
\text { Management } \\
\text { E.3. Risk Management }\end{array}$ \\
\hline
\end{tabular}

\section{Developing advanced digital capabilities and competencies using simulators}

Profound organizational and societal changes are triggered by the speed of technological change and require an agile development and deployment of relevant skills and competencies. Workers must be able to interconnect the organizational challenges with the potentials of technology to come up with innovations that meet the business goals [23]. Digital skills can be defined as the knowledge, skills, and attitudes that enable businesses to exploit ICT opportunities, ensure more efficient and effective performance, explore new ways of conducting business, and establishing new businesses [39].

Advanced digital competencies include adaptive thinking, design mindset, computational thinking, digital collaboration and co-creation, digital analytics, the economics of digital transformation and adequate assessment of digital emerging technologies. Therefore, developing these skills requires intense learning, which can be particularly difficult for SMEs [40][41] for the reasons previously mentioned. In addition, digital transformation in SMEs may require tailored and agile learning adapted to the needs of digital transformation that promotes the company's ability to take advantage of windows of opportunity or unexpected crises [42][43].

Simulation-based learning is a pedagogical strategy that effectively implements a customized learning process to understand the transformative potential of complex technologies [44][45]. This strategy safely allows testing different alternatives using realistic scenarios.

Simulation-based learning has long been used to train professionals in highly complex and risky occupations [46-48], for instance, in aviation. Pilots start by being trained in simulators before they can fly. Every six months, they return to the simulators to learn how to deal with extreme situations [48]. The digital transformation of companies is also complex and risky. Changes in the business model can be so disruptive that they can lead the company to bankruptcy [49][50]. Process automation and the adoption of new technology that is not fully understood can have systemic and unanticipated impacts.

Interest in simulation-based learning has grown rapidly over the last decade [51], its effectiveness being explored both in the context of formal management education and in workplace learning. The complex, 
systemic nature of present management challenges has been identified as crucial for this growing interest.

In recent years, the need to train the industry's workforce has given rise to the concept of smart education, an approach that envisages training in a more flexible and personalized way with digital tools [52]. Simulators and platforms like the one developed by the VOIL project are considered tools that support the flexibility needed to match work demands with the need to develop digital skills in SMEs.

Therefore, previous studies show that simulationbased learning can be considered an effective educational approach in developing new knowledge and skills in the work setting [53]. It may avoid investments and disruptions that can put SMEs' survival at risk. As a technique (not a technology), the simulator can replace and amplify real experiences with guided ones. The guided experiences can evoke or replicate substantial aspects of the real world in a fully interactive fashion [48], continuously training the learners' ability to imagine the tech transfer consequences to planned scenarios in their own company.

How the approach should be applied to improve learning outcomes is still being explored [54], including the design principles to adopt in developing platforms supporting simulation-based learning [55], the best way to achieve specific levels of expertise in training [56] and how to suspend disbelief associated to the artificial environment in which skills are developed [57].

The research into the applicability of simulationbased learning in the workplace serves as a starting point for the VOIL project, which makes available in its online learning environment simulators to explore the potential of 4 technologies to promote the digital growth of SMEs. The simulators are accompanied by step-bystep learning guides. Together with the other developed resources, they allow the proof of the VOIL concept.

\section{Using specific simulators to experiment with emerging technologies}

A simulator is a rich and risk-free environment where learners can make decisions based on certain predefined scenarios before implementing them in real life. The simulation simplifies building virtual environments conducive to the transfer of declarative knowledge for professional action. This transference of knowledge is enhanced by the possibility of experimenting with understandings, adjusting them to the experience acquired in the simulation [58][59].

Our approach focuses on simulators of four types of emerging and disruptive technologies: Digital Twins, Internet of Things (IoT), Blockchain Technology (BCT) and Robotic Process Automation (RPA). These disruptive technologies were selected because they are key enablers of digital transformation. Although there are other technologies that enhance digital growth, namely artificial intelligence, it would not be feasible in the useful time of the project to provide learning guidelines for a large number of simulators. Thus, enough user-friendly simulators were identified to produce a minimal viable prototype of the VOIL learning concept.

Digital Twins allow the digitalization of real-world objects and processes. Digital Twins support the design of complex technical systems by modeling different application scenarios, streamlining the data processing, and enabling detailed simulations at the system level. In this way, they create holistic views of objects and information flows, offer intuitive user interfaces, and leverage shared understandings of opportunities and problems [60][61].

IoT simulators are effective tools to develop, test, evaluate, and analyze the performance of new algorithms, protocols, and techniques, offering high fidelity for scenarios comprising heterogeneous elements [62]. IoT simulators are also used to test options for smart environments, including cities, houses, agriculture and workplaces. Thus, IoT simulators can help to produce tangible results to be used, leveraged, and exploited by IoT product manufacturers, industries, and service providers directly or indirectly to accelerate the creation of smart environments for the benefit of society.

BCT promises trust through secured and immutable digital data exchange and values in decentralized networks. Blockchain simulation tools address several aspects of the complex founding technology [63], including cryptography, distributed computer networks technologies and smart contracts. Therefore, blockchain simulators in our learning environment support developing deeper understandings of blockchain technology's basic capabilities and limitations to fulfill its mission. Well selected blockchain simulators can assist with designing, deploying, testing, and validating blockchain applications for business cases. According to the overall low maturity level of the $\mathrm{BCT}$, gathered insights by using different simulators will be more about overall feasibility for business use cases, rather than the final performance of a Blockchain implementation [62].

The RPA technology supports the digital transformation of processes by automating highly repetitive, routine tasks or completing tasks faster [64][65][66]. It enhances customer experience and improves the general quality of deliverables. RPA used as a simulator can support the organization to learn about the systemic consequences of automation decisions before implementing them in real settings.

A total of 42 simulators in these four categories were found on specialized sites and in scientific 
literature. The simulators were then evaluated regarding (1) type of license (Comercial and Open Source), (2) technical specifications and main features, (3) ease of maintenance, support, documentation and update of the simulator, and (4) interface friendliness. This analysis led to discarding 15 simulators, some due to installation errors or insufficient information (7), others due to their complexity of use (8). For the remaining 27 simulators, the analysis focused on the learning supported and the main functionalities available. It also focused on aspects related to their usability in contexts of self-regulated learning in the workplace.

Finally, the chosen simulators are BCTDemonstrator, MetaMask, and Gaming BlockChain Battle (BlockChain), CupCarbon (IoT), AnyLogic (Digital Twins), and UiPath Studio (RPA).

The learning resources we created include guides to support the self-regulated learning of the four technologies by simulating real-world scenarios using the simulators included in Table 1 .

Table 1. Selected simulators pack

\begin{tabular}{|l|l|l|}
\hline $\begin{array}{l}\text { Disruptive } \\
\text { Technology }\end{array}$ & Simulator & \multicolumn{1}{|c|}{ Simulation capabilities } \\
\hline Block Chain & $\begin{array}{l}\text { Demonstrator, } \\
\text { WetaMask allet, and } \\
\text { Gaming } \\
\text { BlockChain } \\
\text { Battle }\end{array}$ & $\begin{array}{l}\text { Experiment with blockchain } \\
\text { technology, with a particular } \\
\text { focus on learning the } \\
\text { general principles, including } \\
\text { impressions how to } \\
\text { implement and why to audit } \\
\text { smart contracts code }\end{array}$ \\
\hline Digital Twins & Anylogic & $\begin{array}{l}\text { Explore different scenarios } \\
\text { using digital representations } \\
\text { of real settings/objects to } \\
\text { identify impacts of } \\
\text { reorganizations/manipulatio } \\
\text { ns. }\end{array}$ \\
\hline loT & CupCarbon & $\begin{array}{l}\text { Test the behavior of devices } \\
\text { and the flow of data in a } \\
\text { network to support the } \\
\text { development of digital } \\
\text { services. }\end{array}$ \\
\hline RPA & UiPath & $\begin{array}{l}\text { Explore different ways to } \\
\text { optimize processes and } \\
\text { operations, including by } \\
\text { adopting robots. }\end{array}$ \\
\hline
\end{tabular}

The learning guides were developed to support an initial exploration of technology, promoting an understanding of the transformative potential of technology, identifying application areas and exploring different application scenarios. Learning guides have a similar generic structure and include the following main parts: (1) presentation of the technology to be explored with the help of the simulator, (2) the simulator and its main features, (3) the simulation scenario to implement by the learner, (4) debriefing about the simulation experience, (5) self-assessment of learning, and (6) resources to continue learning about the technology.

Our research will implement a self-learning process based on the structure and information of the learning guides, which will allow collecting evidence about the effectiveness of learning supported by the guides.

\section{Discussion of Findings}

The tools and resources developed in our joint research and development project are offered on a platform. The platform is structured in three labs: Assessment Lab, Transformation \& Co-creation Lab, and Simulation Lab. The Assessment Lab encompasses the digital maturity model presented (cf. section 2 ) and the competence assessment tool (i.e., based on the European e-competence Framework) (cf. section 3). The provided resources ensure a structured alignment of digital transformation initiatives with business goals and strategies. Furthermore, the Lab features basic cocreation aspects. For instance, a transformation initiative may be defined individually by a single company or in close collaboration in the context of a cocreation setting. In addition, the Lab provides options to share intermediate results. Thereby, SMEs can learn from each other and collaboratively generate and evaluate digitalization ideas and develop newbusiness models [11][67]. Thereby, this lab in particular serves as a tool to overcome SME-specific challenges of establishing cross-company collaborations [68]. Furthermore, our approach showed that such a contextualized and collaborative approach is suitable for establishing digital capabilities in SMEs. This contributes to IS research on knowledge transfer for SMEs.

The Simulation Lab allows the user to experiment with selected simulators (cf. section 5). Thereby, technologies of previously defined transformation projects can be simulated in a safe environment, e.g., to understand the initiative's value and feasibility better. Through these three Labs, the platform provides an integrated approach for companies to (1) assess their digital maturity, (2) based on the assessment results, define transformation initiatives, and (3) understand and test the intended initiative implementation by using simulators. For example, a competence assessment may reveal a lack of IoT competencies. Thus, we provided first evidence that simulation-based learning is suitable for SMEs in the context of digitization. IS research proposed simulation-based learning for this purpose, e.g. [69][70], but implementation case studies are scarce so far.

Regarding the digital maturity model, a set of companies performed the maturity assessment. Overall, companies showed an intermediate level of maturity 
(i.e., maturity level between 3 and 4 in most of the capacities), while they score a low maturity level (i.e., less than 3) in some capacities that they need to improve. In particular, they show a lack of digitally enabled growth strategies and digital leadership and a low capacity to develop new business models and collaborate with external partners to identify digitally based growth opportunities. They also score low in digital investment and the introduction of digital technologies and cybersecurity. These insights contribute to the call for more research on how digital transformation happens in practice and in particular in SMEs [3].

The Transformation \& Co-creation Lab tools have been applied in eight SMEs in the course of digital transformation projects. The projects involved stakeholders from management positions and lasted between 4 and 6 months. Companies demanded guidance in readily applicable and easy-to-use tools especially in the early phases of digital transformations (i.e., orientation phase) [11]. In particular, the Transformation \& Co-creation Lab tools supported a structured preparation of digital transformation endeavors by aligning digitalization ideas with company goals, transformation drivers, and business model components. In addition, digitalization ideas were arranged on company-specific roadmaps, which serve as a personalized digital transformation agenda. Thus, starting digital transformation requires involvement of stakeholders and IS research needs to find approaches to involve SMEs and to develop personalized roadmaps.

The general structure and feasibility of the learning guides for our technology simulators were pre-tested in some classroom settings and in practitioner workshops. In Austria 15 students and 10 SMEs representatives attended the workshops. In Germany, workshops were attended by 21 students and 31 SMEs representatives and 15 students and 24 SMEs representatives in Portugal. In summary, 10 of the 15 respondents mentioned having benefitted from using the simulators as learning tools and noted that the simulation scenarios are easy to implement and understand. As for ease of use and satisfaction with simulation-based learning, a little more than half indicated that the simulators are easy to handle, not taking much time to learn how to operate it. They also stated that they liked the idea of simulating a specific situation before implementing it in the organization, saying they felt more confident in applying the technology in real situations. Finally, twothirds of respondents said the learning guides helped learn about disruptive technology by integrating clear instructions that can be easily applied in other contexts.

In a second moment, the various labs mentioned in this paper were presented to companies and educators in an interactive workshop. This event resulted in several notes on the discussions that took place as well as responses to a questionnaire presented at the end. From the information collected, recommendations for improvement and adaptations for subsequent implementation emerged. In the event participated 24 professionals, $63 \%$ from SMEs, $29 \%$ from public, nongovernmental organizations and/or universities, and $8 \%$ from large companies.

During the discussions, we confirmed the departing assumptions, namely that most companies attending the event find it challenging to understand how they can transform their business model with the digital technologies in the market and successfully realize the promised value. Participants highlighted the importance of the relationship between industry and university for the digital transformation of the business. Companies bring knowledge of market challenges, whereas universities can support the definition of innovative solutions to these challenges. Therefore, collaboration must take advantage of the complementary knowledge of these partners and this partnership can be extended to the education of future professionals.

Participants highlighted the importance of diagnosing the company's digital skills. Knowing digital maturity in internal skills is the first step to understanding the training needs (reskilling and upskilling).

Regarding the simulators, the participants pointed out that learning based on scenarios, problems, and projects allows critical thinking about complex situations. Therefore, developing skills in small blocks of knowledge helps in the success of the digital transformation of the business.

Table 2: Summary of activities with SMEs.

\begin{tabular}{|c|c|c|}
\hline Country & $\begin{array}{c}\text { N. } \\
\text { Part }\end{array}$ & Main insights \\
\hline Austria & 10 & 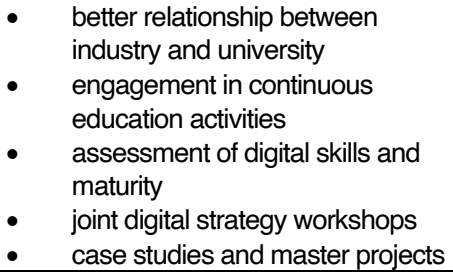 \\
\hline Germany & 31 & $\begin{array}{l}\text { - } \quad \text { closer relationship between } \\
\text { industry and university } \\
\text { diagnose the company's digital } \\
\text { skills in relation to its upcoming } \\
\text { regulatory requirements (EU) and } \\
\text { needed change of the business } \\
\text { model } \\
\text { Actually planed for Q4/21 further } \\
\text { teaching by doing, based on } \\
\text { scenarios, problems and projects, } \\
\text { allows the development of a } \\
\text { critical analysis of concrete } \\
\text { situations. }\end{array}$ \\
\hline
\end{tabular}




\begin{tabular}{|l|l|l|}
\hline & $\bullet$ & $\begin{array}{l}\text { Better relationship between } \\
\text { industry and university } \\
\text { diagnose the company's digital } \\
\text { skills }\end{array}$ \\
Portugal & 24 & $\begin{array}{l}\text { Know digital maturity and internal } \\
\text { skills } \\
\text { teaching by doing, based on } \\
\text { scenarios, problems and projects, } \\
\text { allows the development of a } \\
\text { critical analysis of concrete } \\
\text { situations. } \\
\text { Develop skills in small blocks of } \\
\text { knowledge }\end{array}$ \\
\hline
\end{tabular}

\section{Conclusions}

This paper describes the set of concepts, approaches and tools developed collaboratively by researchers from seven European universities. The paper presents the initial efforts to validate the collaborative project results. The project is still ongoing and implementing new validation activities.

The approaches developed to help companies assess their digital maturity and co-create digital business model transformation initiatives were developed based on prior research by the researchers involved. Regarding the assessment of digital maturity the "DIGROW" framework has been considered, as mentioned above, which is specifically conceived for application in SMEs. This framework represents a relevant research contribution since most frameworks for measuring digital maturity developed so far are focused on big companies [71][72][73].

The researchers' previous experience highlighted the importance of helping SMEs implement selfregulated learning in the workplace as well as providing these companies with basic skills that would allow them to make use of tools available on the web in an open way. For this reason, it was considered important to develop learning guides that can be used to quickly learn the disruptive potential of current technologies and direct these companies to open-source simulators.

The developed resources were aggregated in three virtual labs Assessment Lab, Transformation \& Cocreation Lab, and Simulation Lab. These labs are now implemented in a platform open to be used by any SME. The paper describes the development and validation of the labs. In the second phase of our research, the labs are being integrated on a web platform that will be validated by involving future users: young entrepreneurs and SME workers willing to advance their digital skills.

The validation of the labs allowed us to obtain important feedback that is already being considered in the production of the web platform, namely (1) the need to distribute the e-competencies across the DIGROW dimensions in a more homogeneous way, (2) the importance of the interactive use of resources developed to adjust learning to the specific needs of its users, and (3) offer a learning environment that can be easily integrated with the demands of work in the organization.

The broader validation of the labs will be performed on the most viable prototype of our platform later this year (2021). More qualitative and quantitative empirical data will be gathered and explained soon.

We anticipate that the developed platform will be an advance on to current learning platforms, allowing self-regulated and collaborative approaches that are well adjusted to the specific needs of learners. In addition, we believe that integrating an intelligent layer in the platform to be developed will make it possible to work in an integrated and secure way with the data collected by using the platform, offering recommendations tailored to the specific needs and preferences of the learner.

\section{Acknowledgements}

This work has been supported by VOIL project GRANT_NUMBER: 2019-1-DE01-KA203-005021 and by $\overline{F C T}$ - Fundação para a Ciência e Tecnologia within the R\&D Units Project Scope: UIDB/00319/2020.

\section{References}

[1] EC, European Commission, Annual Report on European SMEs 2017/18, 2018a.

[2] Bounfour, A., "Digital futures, digital transformation", Progress in IS, Cham, Springer International Publishing, v2016.

[3] Vial, G., "Understanding digital transformation: A review and a research agenda", The Journal of Strategic Information Systems, 28(2), 2019, pp. 118-144.

[4] Bharadwaj, A., El Sawy, O.A., Pavlou, P.A., and Venkatraman, N., "Digital business strategy: toward a next generation of insights", MIS Quarterly, 2013, pp. 471-482.

[5] Yeow, A., Soh, C., and Hansen, R., "Aligning with new digital strategy: a dynamic capabilities approach", The Journal of Strategic Information Systems, 27(1), 2018, pp. 43-58.

[6] OECD, Organization for Economic Co-operation and Development, Key issues for digital transformation in the G20, 2017.

[7] Cenamora, J. Paridab, V., and Wincent, J., "How entrepreneurial SMEs compete through digital platforms: the roles of digital platform capability, network capability and ambidexterity", Journal of Business Research, 100, July 2019, pp. 196-206.

[8] North, K., Aramburu, N., Lorenzo, O., and Zubillaga, A., "Digital maturity and growth of SMEs: a survey of firms in the Basque country (Spain)". International Forum on Knowledge Assets Dynamics, Matera (Italy), June 2019.

[9] Aramburu, N., North, K., Zubillaga, A., Salmador, M.P., "A Digital Capabilities Dataset from Small- and Medium-Sized Enterprises in the Basque Country (Spain)", Frontiers in Psychology, 11, 3926, 2021. 
[10] Digital Innovation Hubs Working Group. Report from the working group meeting on access to finance, Brussels (Belgium), February 2018.

[11] Barann, B., Hermann, A., Cordes, A.K., Chasin, F., and Becker, J. "Supporting digital transformation in small and medium-sized enterprises: a procedure model involving publicly funded support units". In Proceedings of the 52nd Hawaii International Conference on System Sciences, January, 2019.

[12] Priyono, A., Moin, A., and Putri, V.N.A.O., "Identifying Digital Transformation Paths in the Business Model of SMEs during the COVID-19 Pandemic", Journal of Open Innovation: Technology, Market, and Complexity, 6. Jg., Nr. 4, S. 104, 2020.

[13] Chen, Y.Y.K., Jaw, Y. L., and Wu, B.L., "Effect of digital transformation on organisational performance of SMEs", Internet Research, 2016.

[14] OECD, The Digital Transformation of SMEs, OECD Studies on SMEs and Entrepreneurship, OECD Publishing, Paris, 2021.

[15] Aramburu, N., North, K., and Zubillaga, A., "Conditioning factors of digitally-enabled growth strategy in SMEs", International Forum on Knowledge Assets Dynamics. Matera (Italy), June 2020.

[16] EC, European Commission, Digital Transformation Scoreboard 2018: evidence of positive outcomes and current opportunities for EU businesses, $2018 \mathrm{~b}$.

[17] Pelletier, C., and Cloutier, L., "Conceptualizing digital transformation in SMEs: an ecosystemic perspective", Journal of Small Business and Enterprise Development, 26, 2019, pp. 855-876.

[18] Tarutea and Gatautis, "ICT impact on SMEs performance", Procedia - Social and Behavioral Sciences, 110, 2014,pp. 1218-1225.

[19] Bouwman, H., Nikou,S., and De-Reuver, M., "Digitalization, business models, and SMEs: how do business model innovation practices improve performance of digitalizing SMEs?", Telecommunications Policy, 43 (9), 101828, 2019.

[20] Shettima, M., and Sharma, N., "Impact of Digitalization on Small and Medium Enterprises in Nigeria", Adalya Journal, 2020.

[21] Pelletier, C., and Cloutier, L.M., "Challenges of digital transformation in SMEs: exploration of IT-related perceptions in a service ecosystem", In Proceedings of the 52nd Hawaii International Conference on System Sciences, January 2019.

[22] Müller, J.M., Buliga, O., and Voigt, K.I., "Fortune favors the prepared: how SMEs approach business model innovations in Industry 4.0", Technological Forecasting and Social Change, 132, 2018, pp. 2-17.

[23] IDC-SAP, I., The Next Steps in Digital Transformation. How small and midsize companies are applying technology to meet key business goals, 2017.

[24] Karltorp, L., "Digital transformation strategies in small businesses: A case study in the Swedish manufacturing industry", Bachelor's Thesis in Business Administration, May 22, 2017.

[25] Baker, H.K., Filbeck, G., and Kiymaz, H. (Eds.), Private equity: opportunities and risks. Oxford University Press, 2015.
[26] EC, European Commission, Grand Coalition for Digital Jobs 2014-2016. Brussels: European Commission, 2016.

[27] McGrath, R.G., and MacMillan, I.C., Discovery driven planning. Philadelphia, PA: Wharton School, Snider Entrepreneurial Center, 1995.

[28] McGrath, R.G., and MacMillan, I.C., "Discovery-driven growth: a breakthrough process to reduce risk and seize opportunity", Harvard business press, 2009.

[29] Gallo, A. "A Refresher on Discovery-Driven Planning", Harvard Business Review, 2017.

[30] Peillon, S., and Dubruc, N., "Barriers to digital servitization in French manufacturing SMEs", Procedia CIRP, 83, 2019, pp. 146-150.

[31] Ley, T., Maier, R., Thalmann, S., Waizenegger,L., Pata, K., and Ruiz-Calleja, A., "A knowledge appropriation model to connect scaffolded learning and knowledge maturation in workplace learning settings", Vocations and Learning, 13(1), 2020, pp. 91-112.

[32] Ulas, D. "Digital transformation process and SMEs", Procedia Computer Science, 158, 2019, pp. 662-671.

[33] Williams, C., Schallmo, D., Lang, K., and Boardman, L., "Digital maturity models for small and medium-sized enterprises: a systematic literature review", ISPIM Innovation Conference - Celebrating Innovation: 500 years since da Vinci, Florence (Italy), June, 2019.

[34] Berghaus, S., Back. A., Kaltenrieder, B., Digital Maturity \& Transformation Report 2017. Institut für Wirtschaftsinformatik, Universität St. Gallen, St. Gallen, Switzerland, 2017.

[35] North, K., Aramburu, N., and Lorenzo, O., "Digitally enabled growth in SMEs: a framework proposal", Journal of Enterprise Information Management, 33 (1), 2020a, pp. 238262.

[36] Teece, D. J., "Explicating dynamic capabilities: the nature and microfoundations of (sustainable) enterprise performance", Strategic Management Journal, 28(13), 2007, pp. 1319-1350.

[37] North, K., Hermann, A. Ramos, I. Aramburu, N., Gudoniene. D., "The VOIL Digital Transformation Competence Framework. Evaluation and Design of Higher Education Curricula", In: Lopata, A., Butkienè, R., Gudonienè, D., Sukackè, V.(Eds.) Information and Software Technologies, 26th International Conference, ICIST 2020, Kaunas, Lithuania, October 15-17, 2020b, Proceedings, Springer (Communications in Computer and Information Science), 2020b, pp. 1-14.

[38] CEN, European e-Competence Framework (e-CF), 2016, https://www.ecompetences.eu/

[39] European e-Skills Forum, E-skills for Europe: towards 2010 and beyond, Synthesis report, September 2004.

[49] Tian, H., Dogbe, C.S.K., Pomegbe, W.W.K., Sarsah, S.A., and Otoo, C.O.A., "Organizational learning ambidexterity and openness, as determinants of SMEs' innovation performance", European Journal of Innovation Management, 2020.

[41] Thorgren, S., and Williams, T. A., "Staying alive during an unfolding crisis: How SMEs ward off impending disaster", Journal of Business Venturing Insights, 14, e00187, 2020.

[42] Casalino, N., Borin, B., Pizzolo, G., and Cavallini, S., "Automation, Technology Transfer and Managerial Practices for Organizational Growth of SMEs. A Smart Curriculum for 
Competitiveness", In 2019 IEEE Global Engineering Education Conference (EDUCON), 2019, pp. 1534-1541.

[43] Giannakos, M.N., Mikalef, P., and Pappas, I.O., "Systematic Literature Review of E-Learning Capabilities to Enhance Organizational Learning", Information Systems Frontiers, 2021,pp. 1-17.

[44] Blanchard, J., "The Simulated Ostomate: An Experiential Caring Experience", Available at SSRN 3165132, 2018.

[45] Threatt, R.M.C., "Incorporating Caring Competencies in the Academic Setting through Simulation", Nursing Theses and Capstone Projects. 279, 2017.

[46] Sarfati,L., Ranchon, F., Vantard, N., Schwiertz, V., Larbre, V.,Parat, S., ... \& Rioufol, C., "Human-simulation-based learning to prevent medication error: A systematic review". Journal of evaluation in clinical practice, 25(1), pp. 11-20, 2019.

[47] Laaziz, E.H., Elkhouzai, E. "An analysis of the permeability of Moroccan higher education to e-learning and simulation based e-learning". International Journal of Technology Enhanced Learning, 10(3), pp. 254-267, 2018.

[48] Lateef, F., "Simulation-based learning: Just like the real thing". Journal of Emergencies, Trauma and Shock, 3(4), $348,2010$.

[49] Strygacz, I., \& Sthub, A. (2018). Combining SimulationBased Training and Flipped Classroom in Project Management Learning, Higher Education Studies, 8(3), pp. 85-93.

[50] Zwikael, O., Shtub, A., \& Chih, Y.Y., "Simulation-based training for project management education: Mind the gap, as one size does not fit all", Journal of Management in Engineering, 31(2), 04014035, 2015.

[51] Hallinger, P., and Wang, R., "Analyzing the intellectual structure of research on simulation-based learning in management education, 1960-2019: A bibliometric review", The International Journal of Management Education, 18(3), 100418, 2020.

[52] Stavropoulos, P., Korfiati, A. M., Panopoulos, N., and Mourtzis, D., "A Smart Learning Model Targeting Regional SME Ecosystems: A Conceptual Framework". Available at SSRN 3859454, 2021.

[53] Salminen- Tuomaala M, Hallila J, Niinimäki A, and Paussu P., "The simulation coaching concept: A step towards expertise", J Nurs Educ Prac., 10:83- 90, 2020.

[54] Chernikova, O., Heitzmann, N., Stadler, M., Holzberger, D., Seidel, T., and Fischer, F., "Simulation-based learning in higher education: a meta-analysis", Review of Educational Research, 90(4), 2020,pp.499-541.

[55] Scholtz, B. M., Kapeso, M., and De Villiers, M. R., "The usefulness and ease of use of a mobile simulation application for learning of ERP systems", South African Computer Journal, 29(2), 2017, pp. 87-105.

[56] Hontvedt, M., and Øvergård, K. I., "'Simulations at work-a framework for configuring simulation fidelity with training objectives", Computer Supported Cooperative Work (CSCW), 29(1), 2020, pp. 85-113.

[57] Muckler, V. C., "Exploring suspension of disbelief during simulation-based learning", Clinical Simulation in Nursing, 13(1), 2017,pp. 3-9.

[58] Díaz, J.L., Leal, C., García, J.A., Hernández, E., Adánez, M.G., and Sáez, A., "Self-Learning methodology in simulated environments (MAESC): Elements and characteristics", Clinical Simulation in Nursing, 12(7), 2016, pp. 268-274.

[59] De Coninck, K., Valcke, M., Ophalvens, I., and Vanderlinde, R., "Bridging the theory-practice gap in teacher education: The design and construction of simulation-based learning environments". In Kohärenz in der Lehrerbildung, Springer VS, Wiesbaden, 2019, pp. 263-280.

[60] Schluse, M., Priggemeyer, M., Atorf, L., and Rossmann, J., "Experimentable digital twins-Streamlining simulationbased systems engineering for industry 4.0 ", IEEE Transactions on industrial informatics, 14(4), 2018, pp. 17221731.

[61] Wagner, R., Schleich, B., Haefner, B., Kuhnle, A., Wartzack, S., and Lanza, G., "Challenges and potentials of digital twins and Industry 4.0 in product design and production for high performance products". Procedia CIRP, 84, 2019, pp.88-93.

[62] Alharby, M., Aldweesh, A., and Van Moorsel, A., "Blockchain-based smart contracts: a systematic mapping study of academic research", In 2018 International Conference on Cloud Computing, Big Data and Blockchain (ICCBB), 2018, pp. 1-6.

[63] Paulavičius, R., Grigaitis, S., and Filatovas, E., "A Systematic Review and Empirical Analysis of Blockchain Simulators", IEEE access, 9, 2021,pp. 38010-38028.

[64] Kirchmer, M., and Franz, P., "Value-driven robotic process automation (RPA)", In International Symposium on Business Modeling and Software Design, Springer, Cham, July 2019, pp. 31-46.

[65] Accenture, "Robotic Process Automation: Future technology in financial services", 2017.

[66] Manyika, J., Chui, M., Miremadi, M., Bughin, J., George, K., Willmott, P. and Dewhurst, M., "Harnessing automation for a future that works", McKinsey Global Institute, 2017.

[67] Aschehoug, S. H., and Ringen, G., "Open Innovation and Idea Generation in SMEs", Proceedings of the International Conference on Engineering Design, ICED, 1(August), 2013, pp. 169-178.

[68] Brunswicker, S., and Ehrenmann, F., "Managing Open Innovation in SMEs: A Good Practice Example of a German Software Firm", International Journal of Industrial Engineering and Management, 4(1), 2013, pp. 33-41.

[69] Benbya, H., Nan, N., Tanriverdi, H., and Yoo, Y., "Complexity and information systems research in the emerging digital world”, MIS Quarterly, 44(1), 2020, pp. 117.

[70] Jung, R., \& Lehrer, C., "Guidelines for education in business and information systems engineering at tertiary institutions", Business \& Information Systems Engineering, 59(3), 2017, pp. 189-203.

[71] McKinsey, "Digital Quotient, McKinsey \& Company: Digital McKinsey”, 2015.

[72] Valdez-de-Leon, O., "A Digital Maturity Model for Telecommunications Service Providers”, Technology Innovation Management Review, 6(8), 2016, pp. 19-32.

[73] Westerman, G., Bonnet, D., and McAfee, A., "The Advantages of Digital Maturity", MIT Sloan Management Review", 2012, November. 